\title{
Training and electrocardiographic abnormalities in the elderly
}

\author{
K. H. SIDNEY' AND ROY J. SHEPHARD \\ From the Department of Preventive Medicine and Biostatistics, University of Toronto, Canada
}

Electrocardiograms (CM5 lead, where one lead is attached in the V5 position and one at the manubrium sterni, with the neutral lead on the back of the neck) have been recorded from 14 men and 25 women aged 60 to 75 years, at rest, during progressive bicycle ergometer exercise to 75 to 85 per cent maximum oxygen intake, and during the subsequent recovery phase. Earlier studies showing a high frequency of ischaemic electrocardiographic abnormalities in women are confirmed; it is suggested that this may reflect a high work load per unit mass of myocardium. Training induces an elevation of the $S T$ segment at rest and during recovery, with a reduction in ST depression during work at a given heart rate, the exercise changes being related to the intensity and frequency of training selected by the subject. Possible explanations of the response to regular exercise include not only the development of the collateral circulation, but also a lessening of the hyperkalaemia of effort and a reduction in the work load per unit mass of myocardium secondary to hypertrophy or a change in the average dimensions of the heart.

The increased frequency of abnormal exercise electrocardiograms with ageing is well documented (Astrand, 1965, 1969; Doan et al., 1965; Blackburn, 1969; Kasser and Bruce, 1969; Profant et al., 1972; Cumming et al., 1972, 1973). In men, it is generally accepted that there is a statistical association between an altered waveform of the ST segment during exercise and myocardial ischaemia, patients with such an abnormality having an increased risk of a 'coronary' attack (Blomqvist, 1965; Blackburn, 1969; Bruce et al., 1969; Kasser and Bruce, 1969; Andersen et al., 1971). In elderly women (Table 1), there is the paradox of an equally high frequency of abnormal records despite a much lower risk of ischaemic heart disease than that seen in the men (Åstrand, 1965; Ostrander et al., 1965; Blackburn, 1969; Profant et al., 1972; Cumming et al., 1973).

Evidence regarding the influence of regular physical activity upon the electrocardiographic changes is conflicting. Saltin and Grimby (1968) noted that in athletes who continued sport into middle-aged and elderly life, ST changes were as common as in the general population, but lower frequencies of abnormalities were observed in exathletes. Roskamm et al. (1964) and Pyorala et al. (1967) had similar findings, but Holmgren and

\footnotetext{
'Present address: School of Physical and Health Education, Laurentian University, Sudbury, Ontario P3E 2C6, Canada. Received for publication 6 December 1976
}

Strandell (1959) reported a relatively high frequency of electrocardiographic abnormalities in ex-athletes. Kavanagh and Shephard (1976) recently examined a substantial series of Masters' class track athletes (age-specific track contests for competitors from the fifth decade (Masters class I), sixth decade (class II), seventh decade (class III), and eighth decade + (class IV); in this group, ST changes were somewhat less frequent than in the general population. Cross-sectional studies suggest benefit from moderate effort. Blackburn (1969) commented that the incidence of post-exercise ST depression was less in farmers than in relatively inactive rail clerks, while Salzman et al. (1969) found that 79 per cent of persons who showed an improvement in physical fitness after training also showed decreases in ST abnormalities during submaximal cycling, improvements being directly related to adherence to the exercise programme and resultant reductions in heart rate at a given load. Bruce et al. (1969) found a 10 per cent decrease of heart rate in submaximal work with a 40 per cent improvement of ST segmental voltages; on the other hand, ST depression was unchanged in symptom-limited maximal work. Several other authors (Mazzarella et al., 1966; Kilbom et al., 1969; Detry and Bruce, 1971; Costill et al., 1974) observed lesser abnormalities at a given work load, but no change in responses at a fixed heart rate after 
Table 1 Frequency of 'positive' exercise tests in elderly subjects

\begin{tabular}{|c|c|c|c|}
\hline $\begin{array}{l}\text { Men } \\
\% \\
\text { Positive }\end{array}$ & Author & $\begin{array}{l}\text { Women } \\
\% \\
\text { Positive }\end{array}$ & Author \\
\hline 37 & Cumming et al. (1972) & 36 & $\begin{array}{l}\text { Brown and Shephard } \\
(1967)\end{array}$ \\
\hline $\begin{array}{l}46 \\
35\end{array}$ & $\begin{array}{l}\text { Doan et al. }(1965) \\
\text { Åstrand (1969) }\end{array}$ & $\begin{array}{r}50 \\
100\end{array}$ & $\begin{array}{l}\text { Astrand (1969) } \\
\text { Profant et al. (1972) }\end{array}$ \\
\hline 32 & Riley et al. (1970) & $33 \star$ & Cumming et al. (1973) \\
\hline 25 & Kasser and Bruce (1969) & 21 & Riley et al. (1970) \\
\hline 17 & $\begin{array}{l}\text { Kavanagh and } \\
\text { Shephard (1976) }\end{array}$ & & \\
\hline
\end{tabular}

*Though the authors cite a frequency of 33 per cent, their figures appear to show 9 of 33 cases (27\%) with ST depression.

training. This implies that any effect of physical activity was the result of a reduction in the total cardiac work load rather than an improvement in myocardial oxygen supply. Kilbom (1971) found an increase in ST segment elevation during work and rest when middle-aged women were trained. However, the two subjects with initial ST depression did not improve.

Kavanagh et al. (1973) carried out experiments on a group of middle-aged 'post-coronary' patients. With training, some reversal of ST depression was found not only at a given work load, but also at a given heart rate; the favourable response was shown largely by younger patients who were able to push themselves to an intensive level of physical activity. Accordingly, it was thought of interest to examine the $S T$ responses of a much older group of men and women, relating changes to the intensity of training undertaken.

\section{Subjects and methods}

The subjects were 14 men and 25 women aged 60 to 75 years. Though volunteers for a preretirement exercise class, the majority were quite sedentary when first enrolled (average bicycle ergometer prediction of aerobic power $22.6 \mathrm{ml} / \mathrm{kg}$ per $\mathrm{min}$ for the men and $21.0 \mathrm{ml} / \mathrm{kg}$ per min for the women, average of direct measurements on the treadmill 29.7 and $26.0 \mathrm{ml} / \mathrm{kg}$ per min for men and women, respectively). Apart from 3 men and 2 women, all were non-smokers. The group had also undergone a medical screening which had eliminated some 21 per cent before exercise testing on the usual clinical indications of unsuitability for participation in the exercise training programme. Specific contraindications to enrolment included uncontrolled metabolic disease, a diastolic pressure of more than $100 \mathrm{mmHg}$, heart failure, orthopaedic disabilities, regular medication other than laxatives or sedatives, history of angina or intermittent claudication, and major abnormalities of the resting electrocardiogram.

All electrocardiograms were recorded with the subjects in a resting but non-basal state. Strenuous physical exertion was avoided on the day of examination, and no meals or cigarettes were consumed within 2 hours of testing. Exercise was performed in an air-conditioned laboratory with a temperature of $22 \pm 2^{\circ} \mathrm{C}$. The subjects wore shorts, and in the case of the women a light halter top. All individuals were familiar with the investigators, and had at least one familiarisation ride on the ergometer before the definitive tests.

The bicycle ergometer was a standard Von Döbeln/Monark design, pedalled at 50 r.p.m. A 12-minute progressive submaximum exercise procedure was followed, with 4 minutes at each stage. The initial loading was 40 to 50 per cent of the estimated maximum oxygen intake and subsequent loadings were adjusted to produce a final heart rate corresponding to 75 to 85 per cent of maximum oxygen intake. After exercise, the subjects remained seated at rest on the bicycle throughout the first 6 minutes of recovery.

During the exercise procedure, the electrocardiogram was recorded by CM5 leads, starting with an initial 6 minutes of rest on the bicycle, continuing through the final 10 seconds of each minute of exercise, and onto the sixth minute of recovery. A Simpliscriptor electrocardiograph (model EK 100, Litton Medical Products) was used throughout. This apparatus meets American Heart Association specifications for high and low frequency response characteristics. Paper speed was set at $25 \mathrm{~mm} / \mathrm{s}$, and the gain was adjusted so that $1 \mathrm{~mm}$ of galvanometer deflection was equal to a signal of $0.1 \mathrm{mV}$. $S T$ voltages were determined by simple inspection on a representative series of complexes, values being averaged over a respiratory cycle. The isoelectric line was defined by joining consecutive PR intervals, and the ST displacement was recorded at the end of the ST segment, immediately before the $T$ wave. ${ }^{1}$

Exercise electrocardiograms were again recorded after 7 and 14 weeks of endurance training. Subjects met for an hour of supervised physical activity 4 times per week. The emphasis was on fast walking and jogging. An initial target pulse rate of 120 to 130 per minute was set, with progression to values of 140 to 150 per minute as the physical condition of the individual permitted. Class members were rated for the vigour and frequency of their participation, so that over the course of the study 4 self-

1This measurement site avoids many of the artefacts that can produce ST depression in healthy young normal subjects (Lepeschkin, 1969). 
Table 2 Initial data showing average deviations of $S T$ segmental voltage (mean $\pm S D$ ) during bicycle ergometer exercise

\begin{tabular}{|c|c|c|c|c|c|}
\hline Time of measurement (min) & Sex & $S T$ segmental voltage $(m V)$ & $f_{h}$ (beats/min) & Work load (Watts) & $\begin{array}{l}\text { Significance of deviation } \\
\text { from isoelectric potential }\end{array}$ \\
\hline $\begin{array}{r}\text { Rest, } 6 \\
\text { Exercise, } 4 \\
8 \\
12 \\
\text { Recovery, } 2 \\
6\end{array}$ & $\begin{array}{l}\text { M } \\
\text { M } \\
\text { F } \\
\text { M } \\
\text { F } \\
\text { M } \\
\text { F } \\
M \\
F \\
M \\
F\end{array}$ & $\begin{array}{r} \pm 0.04 \pm 0.04 \\
+0.01 \pm 0.08 \\
+0.03 \pm 0.08 \\
-0.02 \pm 0.08 \\
-0.02 \pm 0.06 \\
-0.05 \pm 0.10 \\
-0.02 \pm 0.09 \\
-0.04 \pm 0.09 \\
+0.04 \pm 0.13 \\
-0.02 \pm 0.08 \\
+0.02 \pm 0.05 \\
-0.01 \pm 0.08\end{array}$ & $\begin{array}{r}88 \pm 14 \\
80 \pm 13 \\
103 \pm 14 \\
101 \pm 13 \\
118 \pm 10 \\
118 \pm 16 \\
140 \pm 8 \\
135 \pm 10 \\
110 \pm 12 \\
98 \pm 14 \\
100+12 \\
89 \pm 12\end{array}$ & $\begin{array}{l}- \\
\overline{36} \pm 15 \\
22 \pm 9 \\
66 \pm 21 \\
40 \pm 16 \\
97 \pm 30 \\
59 \pm 16 \\
- \\
- \\
-\end{array}$ & $\begin{array}{c}<0.01 \\
\text { NS } \\
\text { NS } \\
\text { NS } \\
\text { NS } \\
<0.01 \\
\text { NS } \\
<0.05 \\
\text { NS } \\
\text { NS } \\
\text { NS } \\
\text { NS }\end{array}$ \\
\hline
\end{tabular}

Note: Elderly subjects $(\mathrm{M}, 14 ; \mathrm{F}, 25), 4$ minutes per stage of progressive test carried to 75 to 85 per cent of maximum oxygen intake.

selected training groups emerged (high frequency, high intensity; low frequency, high intensity; high frequency, low intensity; and low frequency, low intensity).

\section{Results}

\section{INITIAL STATUS}

Under resting conditions (Table 2), the men tended to have a small elevation of the ST segment $(P<0.01)$; in women the group average resting ST voltage did not differ significantly from zero, though 1 woman showed a substantial $(>0.1 \mathrm{mV})$ depression.

During exercise, ST voltages became slightly negative in both men and women, the trend for the women being statistically significant at heart rates averaging 118 and 135 beats per $\min (P<0.01$ and $<0.05$, respectively); however, the averaged data showed no further increase of ST segmental depression from the second to the final work load.

During recovery, there was a gradual return of the ST voltage towards the isoelectric potential, but this process was still incomplete 6 minutes after stopping exercise.

Subjects showing clinically noteworthy ST changes are listed in Table 3. Exercise showed 8 women and 3 men with ST depression greater than $0.1 \mathrm{mV}$. During recovery, 1 further man and 1 further woman developed abnormal records. On the other hand, the 3 men and 4 of the 8 women who showed ischaemia during exercise did not show this phenomenon during recovery. Perhaps because they were health-conscious volunteers, the majority (79\% men, $92 \%$ women) of our subjects were nonsmokers; nevertheless, the percentage of abnormal electrocardiograms $(29 \%$ in the men, $36 \%$ in the women) is much as in previous surveys of sedentary elderly people. Blackburn (1969) and Profant et al. (1972) have also commented that the proportion of abnormalities is influenced but little by smoking habits.

\section{RESPONSE TO TRAINING}

The physiological response to training varied with the self-selected intensity and frequency of effort; gains of maximum oxygen intake for the high frequency, high intensity group were as much as 30 per cent of the initial maximum oxygen intake, whereas changes in the low frequency, low intensity group were small and statistically insignificant (Sidney and Shephard, 1976b).

\section{Resting electrocardiogram}

After 7 weeks of training, there was an insignificant slowing of heart rate $(2.9$ beats $/ \mathrm{min})$. The resting electrocardiogram now showed an elevation of the ST segment; considering the results for both sexes together, the average change was $0.03 \mathrm{mV}$ $(P<0.005)$. At 14 weeks, the slowing of the resting heart rate $(5.4$ beats $/ \mathrm{min})$ was statistically significant

Table 3 Occurrence of ischaemic changes in ST segment of electrocardiogram ( $\geqslant 0.1 \mathrm{mV}$ depression) during bicycle ergometer exercise $(M=14, F=25)$. Intensity of effort was increased progressively to reach 75 to 85 per cent of

$\dot{V} o_{2} \max$

\begin{tabular}{lll}
\hline Occurrence of ischaemic change & $M$ & $F$ \\
Exercise only & 3 & 3 \\
Recovery only & 1 & 1 \\
Exercise and recovery & 0 & $5^{\star}$ \\
\hline Total (exercise and/or recovery) & $4(29 \%)$ & $9^{\star}(36 \%)$ \\
\hline
\end{tabular}

*One woman showed an electrocardiogram which indicated ischaemia at rest and during exercise and recovery. 
$(P<0.005)$. At this stage, there was a further small increase of ST segmental voltage $(0.01 \mathrm{mV})$, but the change from 7 to 14 weeks was statistically insignificant. The extent of the positive deviation was apparently related to the extent of training undertaken; the high frequency, high intensity group showed an $0.06 \mathrm{mV}$ elevation over 14 weeks $(P<0.05)$, and the high frequency, low intensity group also had an increase of $0.05 \mathrm{mV}$ that was nearly significant, but there was no change in the low frequency, high intensity and low frequency, low intensity groups.

\section{Exercise electrocardiogram}

After 14 weeks of conditioning, the men showed decrements in exercise heart rates averaging 14 to 15 beats/min at each of the test work intensities, with increments in ST segment voltages averaging 0.04 to $0.06 \mathrm{mV}$ (Table 4). In the women, the pretraining, post-training differences averaged 3 to 8 beats $/ \mathrm{min}$ for heart rate and 0.01 to $0.07 \mathrm{mV}$ for ST voltage; changes were significant for the first work levels only.

As a second approach to determining whether exercise ST segmental voltages were altered with physical training, we calculated linear regression equations relating ST segmental voltage to exercise heart rate for each individual. The ST segmental voltage corresponding to a fixed heart rate of $120 /$ min was then predicted from these equations. A paired $t$ test analysis of the data indicated that the potential of the ST segment at the fixed heart rate changed from $-0.03 \mathrm{mV}$ to $+0.01 \mathrm{mV}(\mathrm{N}=38$, $\mathrm{P}<0.01$ ), with 7 weeks of training, and from $-0.03 \mathrm{mV}$ to $+0.03 \mathrm{mV}(\mathrm{N}=31, \mathrm{P}<0.025)$, with 14 weeks of training. The increase in potential of the ST segment was equal for both sexes $(0.03$ to $0.04 \mathrm{mV}$ in men and 0.04 to 0.05 in women), but the pretraining, post-training differences were significant only for women. Classifying subjects according to the intensity and frequency of training, changes in the ST segmental voltage were significant only for the high frequency, low intensity group.
Eleven subjects initially showed ST depression greater than $0.1 \mathrm{mV}$ during submaximal exercise. After 14 weeks of training, 5 of the 11 (4 women, 1 man) had improved to the point where the depression was less than $0.1 \mathrm{mV}$ at the selected test heart rates. A further two men who failed to resolve their abnormality with 14 weeks of training did so over an additional 35 to 40 weeks of participation in the exercise class. One further woman had a substantial lessening of ST depression, although her final tracing was still clinically abnormal. The three remaining women showed no evidence of improvement. In addition, 1 woman and 1 man from the low frequency, low intensity group showed ischaemia in the final tests that had not been observed at the initial examination.

\section{Recovery electrocardiogram}

Considering all subjects, the 2-minute post-exercise tracing showed an insignificant elevation of the ST segment $(0.01 \mathrm{mV})$ after 7 weeks of training. An additional 7 weeks of exercise class membership elicited no further changes. The largest elevations were seen in the high frequency, high intensity group (average $0.05 \mathrm{mV}$ ), but even this change was statistically insignificant. At the 6th minute of recovery, there was a $0.04 \mathrm{mV}(P<0.025)$ increase of ST voltage after 14 weeks of training. Changes were again largest for the high frequency, low intensity group ( 7 weeks, $0.06 \mathrm{mV}, \mathrm{P}<0.025,14$ weeks, $0.05 \mathrm{mV}, \mathrm{P}<0.025$ ) and the high frequency, high intensity group ( 7 weeks, $0.05 \mathrm{mV}$ nonsignificant; 14 weeks, $0.09 \mathrm{mV}, P<0.001$ ).

Of the 6 subjects who initially showed clinically noteworthy ST depression after the ergometer test, 4 lost this sign as training proceeded.

\section{Discussion}

\section{ABNORMALITIES IN WOMEN}

The present data support the view of several earlier authors that electrocardiographic abnormalities are at least as common in elderly women as in men of

Table 4 Changes in exercise heart rate and $S T$ segmental voltage with 7 and 14 weeks of training: values are mean differences $\pm S D$

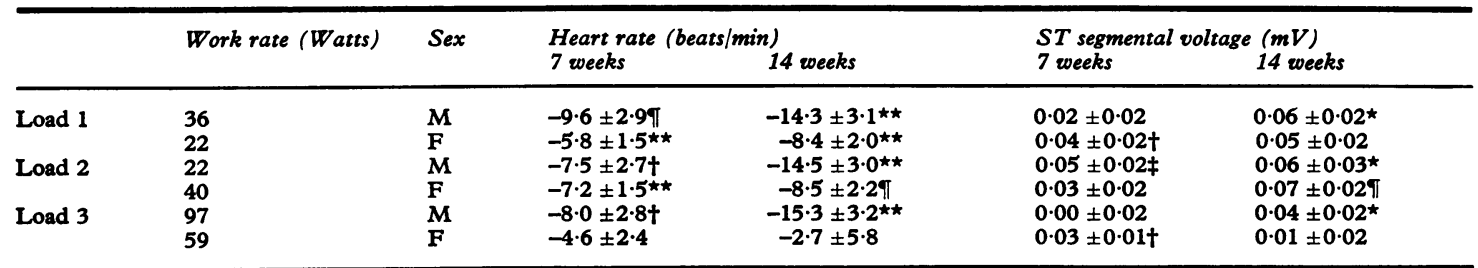

$\star P<0.05,+P<0.025, \ddagger P<0.01, \$ P<0.025, \uparrow P<0.005, \star \star P<0.001$. 
the same age. Several hypotheses have been advanced to explain the phenomenon; in the present instance, a number of these possibilities can be rejected.

(a) It has been suggested that doctors tend to order electrocardiographic tests on women only if clinical symptoms of angina are present (Lepeschkin, 1969). Factors motivating subjects to volunteer for the present study were similar in men and women (Sidney and Shephard, 1976a), so it is unlikely that the proportion of abnormal electrocardiograms in the women was boosted by sample selection.

(b) Since women tend to have a more horizontal ST segment and a smaller $T$ wave than men, it has been postulated that a given segmental depression is more obvious in female subjects (Lepeschkin, 1969). This could explain a high frequency of reported anomalies in 'eyeball' studies (Profant $e t$ al., 1972), but can hardly account for the series of carefully measured records showing frequent ST segmental depressions in elderly women. In the present experiments, data were referred to an isoelectric line drawn between consecutive PR segments; a small $\mathrm{T}$ wave and a more horizontal ST segment could conceivably have displaced our measurement site a little further into the diastolic phase in the women, but this would have reduced rather than increased the proportion of reported abnormalities.

(c) There have been suggestions that sympathetic activity is greater in women than in men at a given level of exercise. However, any difference must be small, since the heart rate at a given percentage of maximal effort is only a little higher in female subjects (Åstrand and Ryhming, 1954). There seems no strong evidence that vasoregulatory asthenia, hyperventilation, postural effects, and related ST artefacts are more prevalent in women than in men.

(d) Women have a higher proportion of body fat than men. The frequency of abnormal ST segmental responses increases with obesity (Blackburn, 1969), though the impact of sex on this correlation does not seem to have been explored.

(e) It has been suggested that women may have as much atheroma as men, and may be as liable to ischaemia during exercise, yet rarely suffer fatal consequences of the disease (Dawber et al., 1957; Astrand, 1965; Kannel and Feinleib, 1972). This would accord with Anderson's hypothesis that heart attacks reflect a 'vulnerable myocardium' (Anderson, 1973); hormonal factors and perhaps secondary differences in tissue mineral reserves serve to protect the female myocardium against ischaemia. At the age of 65 , hormonal advantages of the female are fast waning. The present authors know of no good studies of atheroma and scarring of the myocardium in apparently healthy women; nor, unfortunately, are there data on the vulnerability of the tissues. However, angiograms often fail to support electrocardiograms showing apparent ischaemia in women (Likoff et al., 1966). A further possibility is that the female myocardium has a normal 'vulnerability', but constitutional and cultural factors keep women from the sudden increments in cardiac work load that could precipitate an 'electrical' death; an electrocardiographic test that requires elderly women to work to the same percentage of maximum effort as the men may be culturally unrealistic!

(f) The quadriceps is generally weaker in women than in men. Thus, it might be argued that attempts to perform the same relative work load with weaker muscles give rise to a greater tachycardia, a greater increase of systolic blood pressure, and a greater increase in cardiac work load. Kasser and Bruce (1969) suggest that if the heart of an elderly person is sufficiently loaded, ST segmental depression can arise in the absence of significant coronary disease. In the present experiments, the final blood pressure was only marginally higher in the women than in the men (194 versus $191 \mathrm{mmHg}$ ), while the final exercise heart rate was slightly lower for the women. Total cardiac work loads, therefore, cannot be blamed for the high proportion of ST abnormalities in the women.

(g) Perhaps the most intriguing possible explanation lies in weakness of the cardiac rather than the skeletal muscle. Women typically have smaller hearts than men, and the same absolute cardiac work load thus throws a greater relative strain on unit volume of cardiac tissue. It is most unlikely that the capillary supply per unit mass of muscle is greater in women; thus if a woman is taken to the same heart rate/pressure product as a man, the woman would inevitably be more liable to myocardial ischaemia. Such a deduction reinforces the conclusion of Cumming et al. (1973) that there is a need to revise criteria of abnormality for the female electrocardiogram.

\section{IDENTIFICATION OF MYOCARDIAL ISCHAEMIA}

The present data reinforce the point made by Cumming et al. (1972) in studies of male subjects, that it is desirable to study both exercise and recovery records if all cases with electrocardiographic manifestations of ischaemia are to be identified. The relative prognostic significance of changes during and after effort remains undecided. However, in view of the clinical success of simple submaximal recovery examinations such as the Master test, and 
the reports of emergencies developing shortly after exercise (Bruce et al., 1968; Shephard and Kavanagh, 1975), recovery data should not be rejected.

\section{RESPONSES TO ENDURANCE TRAINING}

The training induced reduction in electrocardiographic abnormalities at a given heart rate and blood pressure is in accord with an earlier study of subjects who trained hard (Kavanagh et al., 1973). Many postcoronary programmes use relatively homoeopathic doses of exercise, and their failure to reduce ischaemia at a given heart rate or pulsepressure product may reflect an insufficient intensity of physical activity. It is less certain that intense training can develop the collateral circulation, as might be expected from work with experimental animals. An alternative hypothesis is that a strengthening of the cardiac muscle and a reduction of mean ventricular radius decreases the work load sustained by unit volume of cardiac tissue.

The situation would then be the antithesis of that in the elderly untrained woman; electrocardiographic evidence of ischaemia would be reduced, but there would not necessarily be any correction of the underlying atheroma. A further possibility is that the well-trained subject releases less intramuscular potassium at a given intensity of effort (Blomqvist, 1969); this, also, would reduce ST changes.

The increase of voltage in the ST segment under resting conditions is not pathological-indeed Sjöstrand (1950) has related the phenomenon to a slow heart rate, while Saltin and Grimby (1968) have commented that endurance athletes show quite distinct ST elevation. Kilbom (1971) has previously seen the development of positive ST segmental voltages in middle-aged women in response to training. The significance of the phenomenon is unknown, though account should probably be taken of the altered resting status in deciding what is a clinically significant ST depression during exercise.

This research was submitted by one of us (K.H.S.) in part fulfilment of the requirements for a Ph.D. degree within the University of Toronto. The support of the Department of National Health and Welfare is acknowledged with thanks.

\section{References}

Andersen, K. L., Shephard, R. J., Denolin, H., Varnauskas, E., and Masironi, R. (1971). Fundamentals of Exercise Testing. World Health Organization, Geneva.

Anderson, T. W. (1973). The vulnerable myocardium. Lancet, 2, 1084-1085.
Åstrand, I. (1965). Exercise electrocardiograms recorded twice with an 8-year interval in a group of 204 women and men 48-63 years old. Acta Medica Scandinavica, 178, 27-39.

Åstrand, I. (1969). Electrocardiographic changes in relation to the type of exercise, the work load, age and sex. In Measurement in Exercise Electrocardiography, pp. 309-321. Ed. by H. Blackburn. Charles C. Thomas, Springfield, Illinois.

Åstrand, P. O., and Ryhming, I. (1954). A nomogram for calculation of aerobic capacity (physical fitness) from pulse rate during sub-maximal work. Fournal of Applied Physio$\log y, 7,218-221$.

Blackburn, H. (1969) (Ed.). Measurement in Exercise Electrocardiography. Charles C. Thomas, Springfield, Illinois.

Blomqvist, G. (1965). The Frank lead exercise electrocardiogram. A quantitative study based on averaging technic and digital computer analysis. Acta Medicia Scandinavica, 178, Suppl. 440.

Blomqvist, G. (1969). Variations of the electrocardiographic response to exercise under different experimental conditions; deconditioning, reconditioning, and high altitude. In Measurement in Exercise Electrocardiography, pp. 323-341. Ed. by H. Blackburn. Charles C. Thomas, Springfield, Illinois.

Brown, J. R., and Shephard, R. J. (1967). Some measurements of fitness in older female employees of a Toronto department store. Canadian Medical Association fournal, 97, 1208-1213.

Bruce, R. A., Alexander, E. R., Li, Y. B., Chiang, B. N., Ting, N., and Hornsten, T. R. (1969). Electrocardiographic responses to maximal exercise in American and Chinese population samples. In Measurement in Exercise Electrocardiography, pp. 413-444. Ed. by H. Blackburn. Charles C. Thomas, Springfield, Illinois.

Bruce, R. A., Hornsten, T. R., and Blackmon, J. R. (1968). Myocardial infarction after normal responses to maximal exercise. Circulation, 38, 552-558.

Costill, D. L., Branam, G. E., Moore, J. C., Sparks, K., and Turner, C. (1974). Effects of physical training in men with coronary heart disease. Medicine and Science in Sports, 6, 95-100.

Cumming, G. R., Borysyk, L., and Dufresne, C. (1972). The maximal exercise ECG in asymptomatic men. Canadian Medical Association fournal, 106, 649-653.

Cumming, G. R., Dufresne, C., Kich, L., and Samm, J. (1973). Exercise electrocardiogram patterns in normal women. British Heart fournal, 35, 1055-1061.

Dawber, T. R., Moore, F. E., and Mann, G. V. (1957). Coronary heart disease in the Framingham study. American fournal of Public Health, 47, Suppl. 4-23.

Detry, J-M., and Bruce, R. A. (1971). Effects of physical training on exertional ST segment depression in coronary heart disease. Circulation, 44, 390-396.

Doan, A. E., Peterson, D. R., Blackmon, J. R., and Bruce, A. R. (1965). Myocardial ischemia after maximal exercise in healthy men. A method for detecting potential coronary heart disease? American Heart fournal, 69, 11-21.

Holmgren, A., and Strandell, T. (1959). Relationship between heart volume, total hemoglobin, and physical working capacity in former athletes. Acta Medica Scandinavica, 163, 149-160.

Kannel, W. B., and Feinleib, M. (1972). Natural history of angina pectoris in the Framingham study. American fournal of Cardiology, 29, 154-163.

Kasser, I. S., and Bruce, R. A. (1969). Comparative effects of aging and coronary heart disease on submaximal and maximal exercise. Circulation, 39, 759-774.

Kavanagh; T., and Shephard, R. J. (1976). Characteristics of the master Athlete. Proceedings of the National Academy of Sciences of the United States of America. In the press. 
Kavanagh, T., Shephard, R. J., Doney, H., and Pandit, V. (1973). Intensive exercise in coronary rehabilitation. Medicine and Science in Sports, 5, 34-39.

Kilbom, A. (1971). Physical training in women. Scandinavian fournal of Clinical and Laboratory Investigation, 28, Suppl. $119,1-34$.

Kilbom, A., Hartley, L. H., Saltin, B., Bjure, J., Grimby, G., and Astrand, I. (1969). Physical training in sedentary middle-aged and older men. I. Medical evaluation. Scandinavian fournal of Clinical and Labaratory Investigation, 24, 315-322.

Lepeschkin, E. (1969). Physiological factors influencing the electrocardiographic response to exercise. In Measurement in Exercise Electrocardiography, pp. 363-387. Ed. by H. Blackburn. Charles C. Thomas, Springfield, Illinois.

Likoff, W., Segal, B. L., and Kasparian, H. (1966). Paradox of normal selective coronary arteriograms in patients considered to have unmistakable coronary heart disease. Circulation, 34, Suppl. 3, 157.

Mazzarella, J., Skinner, J. S., and Evans, T. (1966). Effects of interval training on the exercise electrocardiogram. Circulation, 34, Suppl. 3, 165.

Ostrander, L. D., Brandt, R. L., Kjelsberg, M. O., and Epstein, F. H. (1965). Electrocardiographic findings among the adult population of a total natural community, Tecumseh, Michigan. Circulation, 31, 888-898.

Profant, G. R., Early, R. G., Nilson, K. L., Kusumi, F., Hofer, V., and Bruce, R. A. (1972). Responses to maximal exercise in healthy middle-aged women. Fournal of Applied Physiology, 33, 595-599.

Pyorala, K., Karvonen, M. J., Taskinen, P., Takkunen, J., and Kyronseppa, H. (1967). Cardiovascular studies on former endurance athletes. In Physical Activity and the Heart, pp. 301-310. Ed. by M. J. Karvonen and A. J. Barry. Charles C. Thomas, Springfield, Illinois.

Riley, C. P., Oberman, A., Lampton, T. D., and Hurst, D. C. (1970). Submaximal exercise testing in a random sample of an elderly population. Circulation, 42, 43-51.
Roskamm, H., Reindel, H., Weissleder, H., Kessler, G., and Aletter, K. (1964). Zur Frage der Spätschäden nach intensiven Hochleistungsport. Medizinische Welt, 2, 2170-2180.

Saltin, B., and Grimby, G. (1968). Physiological analysis of middle-aged and old former athletes. Comparison with still active athletes of the same ages. Circulation, 38, 1104-1115.

Salzman, S. H., Hellerstein, H. K., Radke, J. D., Maistelman, H. W., and Ricklin, R. (1969). Quantitative effects of physical conditioning on the exercise electrocardiogram of middle-aged subjects with arteriosclerotic heart disease. In Measurement in. Exercise Electrocardiography, pp. 388410. Ed. by H. Blackburn. Charles C. Thomas, Springfield, Illinois.

Shephard, R. J., and Kavanagh, T. (1975). Mild or intense exercise in coronary rehabilitation? In Proceedings, 20th World Congress of Sports Medicine, Melbourne, Australia.

Sidney, K. H., and Shephard, R. J. (1976a). Attitudes towards health and physical activity in the elderly. Effects of a training programme. Medicine and Science in Sports, 8, 246-252.

Sidney, K. H., and Shephard, R. J. (1976b). Frequency and intensity of exercise as determinants of the response to training in elderly subjects. Medicine and Science in Sports. Submitted for publication.

Siegel, W., Blomqvist, G., and Mitchell, J., II. (1970). Effects of a quantitated physical training program on middle-aged sedentary men. Circulation, 41, 19-29.

Sjöstrand, T. (1950). The relationship between the heart frequency and the ST level of the electrocardiogram. Acta Medica Scandinavica, 138, 200-210.

Requests for reprints to Professor Roy J. Shephard, 150 College Street, Toronto M5S 1A1, Ontario, Canada. 